Received: 21. 04.2021.

doi: 10.46763/JESPT21161009sv

udc: $572.087 .1-053.5-057.875$

Revised: 13.05.2021.

Accepted: 17.05 .2021

\title{
ASSOCIATION BETWEEN SOCIOECONOMIC STATUS AND THE BODY MASS INDEX OF 6 TO 9-YEAR-OLD CHILDREN IN URBANAND RURAL AREAS
}

\author{
Snezana Stavreva Veselinovska ${ }^{1}$ \\ 'Faculty of Educational Sciences, Goce Delcev, University - Stip Republic of North Macedonia \\ snezana.veselinovska@ugd.edu.mk
}

\begin{abstract}
Overweight and obesity are leading to nutrition-related disorders of clinical and public health concern. Assessment and classification of these conditions are dependent on specific body mass index (BMl; in kg/ $\mathrm{m}^{2}$ ) cutoff points. The body mass index (BMI) is the metric currently in use for defining anthropometric height/ weight characteristics in adults and for classifying (categorizing) them into groups. The common interpretation is that it represents an index of an individual's fatness. It also is widely used as a risk factor for the development of or the prevalence of several health issues. In addition, it is widely used in determining public health policies.The $\mathrm{BMI}$ has been useful in population- based studies by virtue of its wide acceptance in defining specific categories of body mass as a healthissue. However, it is increasingly clear that BMI is a rather poor indicator of the percentage of body fat. Importantly, the BMI also does not capture information on the mass of fat in different body sites. The latter is related not only to untoward health issues, but to social issues as well. Lastly, current evidence indicates there is a wide range of BMls over which mortality risk is modest, and this is age related. All of these issues are discussed in this brief review.
\end{abstract}

Key words: Body mass index, overweight, obesity, healthy weight, health issues.

\section{Intoduction}

Obesity is a serious public health concern because of numerous effects on physical (including cardiovascular, metabolic, and other chronic diseases) and psychosocial health, (World Health Organization). Studies in Hedley et all, 1999 - 2002 and Zimmermann MB, Gübeli C, Püntener C, Molinari $L$ in many countries have demonstrated increases in the prevalence of overweight in children and youth in recent years. One factor consistently associated with obesity in children and adults is socioeconomic status (SES). In developed countries, SES is inversely associated with obesity (Sarlio-Lähteenkorva S, Lissau I, LahelmaE,; Drewnowski A, Specter SE, and Delva J, O'Malley PM, Johnston LD, 2007). Another well-established risk factor for overweight in children and youth is media use, (Harrison K, MarskeAL, 2005) which is thought to reduceenergyexpenditurethroughthe displacement of physical activity and to increased food intake when children eat while watching television. Television viewing may also prompt the eating of high-calorie snacks, convenience foods, fast foods, andsweets through the influence of food advertisements. There is a clear need to better understand the mechanisms behind the development of obesity during childhood. There is also reason to believe that media use is higher in low-SES groups (Grund, 2001). For example, in a study of North Carolina adolescents, Jackson et al found much higher televisionand movie viewership in adolescents. These findings suggest that media exposure could be 1 mechanism underlying the well-documented SES-body mass index (BMI) (calculated as weight in kilograms divided by height in meters squared) relationship, especially in children. However, we could not find a study that explicitly models media use as a mediating factor; instead, it is usually considered as an independent risk factor for obesity. Overweight is defined as a body weight that exceeds the acceptable weight for a particular person, based on the individual's age, height and/or frame size (Kuczmarski, 2000). It is also defined as a body mass index (BMI) of 25- $29.9 \mathrm{~kg} / \mathrm{m}$; whereas, obesity is 
defined as a BMI greater 2 thanor equal to $30 \mathrm{~kg} / \mathrm{m}$ (WHO, 1998; Uwaifo and 2 Arioglu, 2004). Several classifications and definitions exist for degrees of obesity, the most widely accepted being the World Health Organization (WHO) criteria, based on BMI (Uwaifo and Arioglu, 2004). Body mass index is a measure of ponderosity or heaviness and it is calculated by dividing weight in kilogrammes byheight in metres squared - Wkg/Hm (Himes, 1999). According to Uwaifo and 2 Adedoyin (2005), BMI is far more commonly used to define obesity and has been found to closely correlate with the degree of body fat in most settings. Obesity constitutes a significant public health problem in the developed world (WHO, 1997; Siedel, 1997; Sorenson, 2000; Uwaifo and Adedoyin , 2005). The prevalence is also increasing rapidly in several developing nationsworldwide, and it is associated with high morbidity and mortality (Uwaifo and Arioglu, 2004). Obesity, which is often perceived as a cosmetic problem in adults, is associated with high blood pressure, type 2 diabetes and abnormal levels of total cholesterol (Gail et al, 2005; Colhoun et al, 1998). The recent upsurge in its prevalence in developing countries is believed to be linked to the acculturation resulting from Westernization that these nations are undergoing, with alterations in diet and activity patterns (WHO, 1997; Popkin, 1994). The etiology of obesity is multifactorial, genetic predisposition and environmental factors having been implicated in most studies (Maes et al, 1997; Hill et al, 2000). In the past, however, the socioeconomic status (SES) has been an important factor associated with high incidences ofobesity Flegal et al, 2002; Lyratzopoulos et al, 2005). Several studies using individual measures of socioeconomic (SE) variables such as income, education and occupation, haveshown that individuals in the lower SE strata are more likely to be obese as shown by an increase in BMI with decreasing SE scores. (Hardy et al, 2000; Lyratzopoulos et al, 2005). Studies conducted in the US also show that people in the lower SE stratum and minority groups have a higher prevalence of obesity (Sobal and Stunkard, 1989). According to Uwaifoand Arioglu (2004), data from Africa on this issue is scant, though a clear and distinct seculartrend of profoundly increasing BMI clearly exists when people from Africa migrate to the countries in the Northwestern hemisphere.

\section{Subject of research}

The subject of this research is the impact of the socio-economic position of the familyon the physical status as well as the occurrence, frequency and treatment of some of the mostcommon diseases and deformities in school children compared in urban and rural areas.

This research and theoretical discussion will contribute significantly to the enrichment and advancement of pedagogical theory and practice, it will present the possible reasons for the occurrence of such changes in the physical development of students and the occurrence of some diseases, and thus it will improve the relationship not only of families to children but also of all relevant social structures that directly or indirectly influence these more frequent occurrences.

This problem is complex and covers a series of phenomena and processes that take place in families and in the social environment, and their mutual relations.

The subject of research will include the following factors:

- Completeness of the family;

- Financial status of the family;

- Parents' education;

- Physical development of children expressed through BMl;

- Occurrence and frequency of some diseases that more often afflict students in classteaching of primary school.

The research was conducted on the territory of the Municipality of Kocani, in March and April in 2017. in the central city primary school "Ss Cyril and Methodius" as a school located in the urban area and the regional primary school in the village of Podlog as a schoollocated in the rural area. The research included students from first, fourth and ninth grade aged 6 to 14 years, in both schools as well as their parents. 


\section{Goal and character}

This study aims to investigate whether there is an impact of the family's socioeconomicstatus on the physical status of students in the family as well as the occurrence, frequency and treatment of some of the most common diseases and deformities in school children compared in urban and rural areas.

The research is qualitative and quantitative. The research was conducted individually.

\section{Tasks}

In accordance with the defined goal of the research, the following tasks were set and specified:

1. To examine whether the socio-economic status of the family affects the physical development of students;

2. To examine whether the socio-economic status of the family does not affect the physical development of students;

3. To examine whether the socio-economic status of the family affects the occurrence, frequency and treatment of some of the most common diseases and deformities in school children compared to urban and rural environments.

To examine whether the socio-economic status of the family does not affect the occurrence, frequency and treatment of some of the most common diseases and deformities in school children compared to urban and rural environments.

To examine the economic situation of the families and of the students who have deviationsin the physical development.

\section{Hypotheses}

Based on the purpose and tasks of the research, we set the following hypotheses: General hypothesis

1. We assume that there is an impact of the socio-economic status of the family on thephysical status of students as well as the occurrence, frequency and treatment of some of the most common diseases and deformities in school children compared to urban and rural areas.

From the general hypothesis, and in accordance with the previously set tasks, the special - auxiliary hypotheses arise:

1. There is a statistically significant relationship between the socio-economic status of the family and the physical status of students in the family as well as the occurrence, frequency and treatment of some of the most common diseases and deformities in school children compared to urban and rural areas.

2. Parents with higher educations and parents who earn more can prevent the occurrence and treatment of some of the most common diseases and deformities in school children.

3. There is a statistically significant relationship between material conditions in the family andthe frequency and treatment of some of the most common diseases and deformities in schoolchildren.

4. It is assumed that the family atmosphere influences the positive growth and development of students.

5. It is assumed that students with lower BMI come from poor families.

6. It is assumed that parenting style and high level of communication (open communication) between family members can prevent impaired physical development and the occurrence of some of the diseases.

\section{Variables}

The independent variable in the research is the family with its characteristics: completeness (complete, incomplete families), economic status (family standard, employment status: employment / unemployment, personal income, housing), parents' educational level.

The dependent variables in the research are: height and weight, BMI, diseases. 


\section{Methods, techniques and instruments}

The research will be mainly carried out using the descriptive method with all its modalities, in the form of a description, during which the obtained results were analyzed and generalized.The influence of the independent on the dependent variables was analyzed using the causal method.

The following research techniques will be applied according to the set tasks:

- Survey

- Scaling

The application of these techniques will be done with specially designed research

\section{instruments:}

Questionnaires for students and parents through which data will be obtained about the family in which the student lives;

- From the data obtained on the family, the socio-economic status is calculated.

- Scales for the assessment of students' families (descriptive, numerical, graphic). The Likert scale is used for the scaling method.

Survey - This technique will be used to obtain the opinions and views of students in schools as well as of parents. Two questionnaires will be used as instruments, one intended for parents, and the other intended for examining the opinions and attitudes of students regarding the situation in their family.

The questions in the questionnaire will be divided into two parts.

The first part will contain general data regarding respondents and their families.The second part refers to the situation in the family and the way of upbringing.

\section{Population and sample}

The research covers population categories of students and parents. Two primary schools from the municipality of Kocani are included. The starting criterion for selecting schools is their location because one of the goals of the paper is to make a comparative reviewof the results obtained from urban and rural areas. We have a primary school in the central city area in the municipality of Kocani - the primary school "Ss Cyril and Methodius" and the regional school in the village of Podlog belonging to the primary school "Ss Cyril and Methodius".

The population in this research is final, and it refers to the students from the first, fourthand fifth grade, from the two primary nine-year schools in the municipality of Kocani, the elementary school "Ss Cyril and Methodius" and the regional school in the village of Podlog belonging to the elementary school "Ss. Cyril and Methodius", in March and April in the schoolyear 2016/2017. Their parents are also the population of the survey.

The total number of students surveyed is 125 from both primary schools. 88 of them are from the primary school "Ss Cyril and Methodius", and 37 from the regional school in the village of Podlog. The total number of parents respondents will also be 125, because for eachstudent who gets a questionnaire, one will be also be given to one of the parents.

The total number of respondents (students and parents) is 250, i.e. in the primary school "Ss Cyril and Methodius" 176 respondents, of which 88 students and 88 parents and in the regional school in the village of Podlog 74 respondents, i.e. 37 students and 37 parents.

Table 1. Sample structure of respondents

\begin{tabular}{|c|c|}
\hline Respondents & Total \\
\hline Students & 125 \\
\hline Parents & 125 \\
\hline Total: & 250 \\
\hline
\end{tabular}


Table 2. Sample structure (students) by primary schools

\begin{tabular}{|c|c|}
\hline \multicolumn{2}{|c|}{ Primary school } \\
\hline "Ss Cyril and Methodius" Kocani & 88 \\
\hline Regional school village Podlog & 37 \\
\hline
\end{tabular}

Table 3. Sample structure by strata expressed by frequencies and percentage

\begin{tabular}{|c|c|c|}
\hline STRATUM & Frequency (F) & Percentage (\%) \\
\hline Students & 125 & 50 \\
\hline Parents & 125 & 50 \\
\hline Total & 250 & 100 \\
\hline
\end{tabular}

\section{STRATUM: STUDENTS AND PARENTS EXPRESSED IN PERCENTAGES}

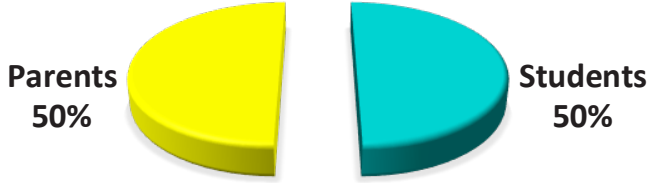

Chart 1. Stratum: Students and parents expressed in percentages

- Primary school "Ss Cyril and Methodius" - Kocani has a total of 176 respondents or $65 \%$ of the total number of respondents, of which 88 students and 88 parents.

- Regional school belonging to the primary school "Ss Cyril and Methodius" - village Podlog - has a total of 37 respondents or $35 \%$ of the total number of respondents, of which 37 studentsand 37 parents.

Table 4. Structure of the sample divided by schools, expressed in frequencies andpercentages

\begin{tabular}{|l|c|c|}
\hline \multicolumn{1}{|c|}{ SCHOOL } & Frequency (F) & Percentage (\%) \\
\hline Primary school “Ss Cyril andMethodius” Kocani & 176 & 67 \\
\hline Regional primary school village Podlog & 74 & 33 \\
\hline Total & 250 & 100 \\
\hline
\end{tabular}

Table 5. Structure of the sample of students by schools

\begin{tabular}{|l|c|c|}
\hline \multicolumn{1}{|c|}{ Primary school } & Municipality & Number of students \\
\hline Primary school “Ss Cyril andMethodius” Kocani & Kocani & 88 \\
\hline Regional school village Podlog & Kocani & 37 \\
\hline \multicolumn{2}{|c|}{ Total: } & 125 \\
\hline
\end{tabular}


Table 6. Structure of the student sample in PS "Ss Cyril and Methodius"

\begin{tabular}{|c|c|}
\hline Primary school "Ss Cyril and Methodius" Kocani & Number of students by grades \\
\hline First grade & 26 \\
\hline Fourth grade & 17 \\
\hline Ninth grade & 23 \\
\hline Total: & 88 \\
\hline
\end{tabular}

Table 7. Structure of the student sample in the regional school village Podlog

\begin{tabular}{|c|c|}
\hline Regional school village Podlog & Number of students \\
\hline First grade & 12 \\
\hline Fourth grade & 11 \\
\hline Ninth grade & 14 \\
\hline Total: & 37 \\
\hline
\end{tabular}

In this research, we opted for the first and the fourth grade students because they arechildren from 6 to 9 years of age with the new concept of the nine-year education when children start school at 6 years of age and it is a period when there are still no physiological changes compared to the ninth grade students who enter the stage of puberty and visible changes in their growth and development are already noticeable.

The sample of parents is connected with the sample of students, i.e. one of the parentsof all students also got questionnaires.

The research included 125 respondents - students from the two primary schools in themunicipality of Kocani and the same number of parents respondents. The chi-square test isolated three variables that proved to be statistically significant: mother's education, father's education and socio-economic status of the family. The results obtained show that the educational inferiority of parents and the weaker socio-economic situation in the family have an impact on the physical development as well as on the occurrence, frequency and treatmentof some of the diseases that occur more often in school-age children.

\section{Statistical processing}

The results obtained from the research of a representative sample with generalization will be processed with research techniques - classification of family structure and the impact on the physical development of the first, fourth and ninth grade students and on the occurrence, frequency and treatment of some of the most common diseases in school-age children.

The obtained data are presented as a percentage, numerically and with graphs. The processing of the obtained results is done quantitatively and qualitatively. Quantitative and qualitative analysis were used to analyze the answers to the questions from the students' andparents' questionnaires. The results were sorted, grouped and then entered into tables. By distributing the data, the cumulative groupings were made according to frequency. By calculating the percentages for obtaining average results were performed special groupings. The results have several levels of processing through the application of research techniques:

1. All results will be classified in the envisaged categories for: the educational level of parents, occupations and the number of members in the family through which the socio-economic status is calculated as one of the set goals in the research;

2. Classification of students according to height and weight measurements and obtaining their BMl;

3. Classification will be performed individually by grades and generally by schools;

4. The results are presented numerically, in percentage and graphically; 
5. The correlation coefficient between the socio-economic status of the family and the physical development of the students through BMI and BMP is calculated.

6. A comparison is made between the results obtained from urban and rural areas;

7. The correlation coefficient indicates whether there is a correlation between thesetwo variables (SES and BMI).

\section{Results and discussion}

We have assessed the analysis of the socio-economic status of the surveyed students'families as necessary, given the assumption that this factor plays a significant role in the physical development of children and in the occurrence of some of the diseases characteristicof school age. It can be rightly assumed that the low social status entails more difficult and less favorable living conditions and thus has an impact on the development and behavior of young people in a negative direction. The socioeconomic status differently affects the formation of value orientations in young people, and thus formed value orientations directly determine the manner of behavior, in a permissible or impermissible direction.

In the conducted questionnaire there was the question - Are you engaged in sports and sporting activities?

In the results obtained, the noticeable fact that almost half of the respondent's state that they do not engage in sports and sporting activities, both in urban and rural areas, is worrying. Is the modern way of life, enabled by advanced technology, an issue that is unfortunately increasingly imposed today and that contributes to a significant reduction in physical activity among the entire population, especially among school-age children, which ischaracterized by a long stay at school, sitting and working on school desks and computers, as well as the increasing use of various motor vehicles when performing numerous daily activities? All this contributes to children's physical inactivity, which directly affects the weakening of the musculoskeletal system, as well as to the occurrence of obesity, which are a sure prerequisite for the occurrence of various deformities of the spine, feet, and other partsof the body.

We can conclude from this that there is a small difference in the answers to the question - Are you engaged in sports and sporting activities? - between respondents from bothenvironments, urban and rural.

Table 8. Structure of the sample according to whether they are dealing with sports andsports activities

\begin{tabular}{|l|c|c|c|c|}
\hline \multicolumn{5}{|c|}{ Are you engaged in sports and sporting activities? } \\
\hline Place & Yes & $\%$ & No & $\%$ \\
\hline Kocani & 45 & $51 \%$ & 43 & $49 \%$ \\
\hline village Podlog & 22 & $59 \%$ & 15 & $41 \%$ \\
\hline
\end{tabular}

If we analyze the data for the total sample of the surveyed students in urban and ruralareas, it can be noticed that the percentage of students from the primary school "Ss Cyril andMethodius" in Kocani is almost the same. There is a deviation in students from the regional school in the village Podlog where, compared to others, there is a higher percentage of students who engage in sports.

One of the reasons why we decided to analyze such a stratified sample in terms of theliving environment (urban - rural) was our expectation that there would be differences in relation to students who (do not) engage in certain sports activities in the village - city. 
Although this issue has been the subject of study by many researchers, this researchis not intended to devalue the results of numerous sociological and pedagogical studies whoseprimary goal was to study the socio-economic status.

In the research we also measured the students' height and weight in the first, fourth and ninth grade of the primary school "Ss Cyril and Methodius" in Kocani and the regional school "Ss Cyril and Methodius" in the village of Podlog where the students from the first, fourth and ninth grade were also included.

From the results of the measurement of the students' body height and weight, it can be noticed that in the first grade the height moves in the range of $120-140 \mathrm{~cm}$. According tothe age of the firstgrade students, it can be concluded that this is a normal height for the givenage.

Table 9. Structure of the sample according to the height of the students of the first grade in the elementary school "Ss Cyril and Methodius" in the school "Ss Cyril and Methodius" primary school in the village of Podlog.

\begin{tabular}{|c|c|c|}
\hline \multicolumn{3}{|c|}{ Body height $(\mathrm{cm})$} \\
\hline $\begin{array}{c}\text { Kocani First } \\
\text { grade }\end{array}$ & $\begin{array}{c}\text { Village Podlog } \\
\text { First grade }\end{array}$ \\
\hline $80-100 \mathrm{~cm}$ & 2 & 0 \\
\hline $100-120 \mathrm{~cm}$ & 9 & 1 \\
\hline $120-140 \mathrm{~cm}$ & 11 & 10 \\
\hline $140-160 \mathrm{~cm}$ & 1 & 1 \\
\hline
\end{tabular}

The results also show that in nine first grade students in the primary school "Ss Cyril and Methodius" in Kocani a lower height was measured (100 to $120 \mathrm{~cm}$ ), which deviates fromthe normal height (120140), while in both schools we had one student respectively whose height was slightly higher than normal. The values of $140-160 \mathrm{~cm}$ were measured in these twostudents.

From the results obtained in measuring the students'body weight in the primary school'Ss Cyril and Methodius" in Kocani, it can be noticed that in the first grade the body weight ranges from 15 to 25 $\mathrm{kg}$; according to the age of the first-grade students, it can be concludedthat this is a normal weight for the given age. On the other hand, the results obtained from the regional school primary school "Ss Cyril and Methodius" in the village of Podlog clearly showthat most of the students weighed 35-45 kg. In the continuation of the research, we will try todetermine the reason for this difference and the possibility to influence its improvement.

From the measurements of the body weight of the fourth grade students from the twoschools "Ss Cyril and Methodius" Kocani and Podlog, from the total number of 88 respondents in Kocani in 20 of them we can see that the students weighing 20-40 kg predominate; also, the body weight of 12 students was measured among the respondents from the regional school "Ss Cyril and Methodius" in the village of Podlog, which is also in the range of $20-40 \mathrm{~kg}$.

From this we can conclude that students from rural areas have increased body weight.

These students come from families with a lower socioeconomic status.

The results obtained refute the first auxiliary hypothesis that the high socio-economic status has a positive effect on students.

The results of our study are of particular importance in relation to boys classified as clinically at risk of being overweight, and who are less likely than other boys or girls to try to lose weight, and who are also less likely to receive dietary and weight control advice from significant other people. Despite this apparent lack of interest in weight control and advice from other persons, these overweight boys, especially those in the lower SES (socio-economicstatus) groups, retained positive physical selfconfidence. 
In spite of the lack of qualitative data in the study, it seems likely that these overweightboys simply are not as concerned about their being "big" as the overweight boys of the uppersocial class, and that other people around them, such as their parents, are similarly not worried. These results are similar to those of Steenetal who found that obese adolescent boysappeared to be relatively unconcerned about their physical appearance and not particularly interested in losing weight (Steenetal, 1996).

Another explanation for their lack of interest in losing weight and the increased interestin gaining weight in these boys is that they may be overly muscular rather than overweight and may tend to gain weight in the form of muscle mass, as has been cited in some recent studies (McCreary and Sasse, 2000; O'Dea and Rawstorne, 2001). While body mass index isgenerally considered an appropriate measure of overweight in children and adolescents (Hammeretal, 1991), the additional use of the measure of adiposity or muscularity may be explained in some other studies.

The research results also suggest that young people with low SES, especially boys, may be particularly resistant to the socio-cultural influences that shape the image of the body, and that it is possible that their respect for the body, in fact, can be strengthened because theyhave a body larger than their peers. As for children with low SES in our study, especially boys,not only are they more likely to be overweight and skip breakfast regularly, but they are also more likely to see themselves as "too thin" and trying to gain weight, compared to their peerswith a higher SES. Lower-class children received less nutritional advice than other children and maintained positive physical self-esteem despite being overweight. It is possible that theappearance of these young people's bodies was somewhat protected by not receiving weightmanagement advice and accompanying thinness/slenderness doctrine that promotes dissatisfaction with the body.

In the research process, measurement was also conducted in the ninth grade in the primary school "Ss Cyril and Methodius" in Kocani on 40 students. We can conclude that in the ninth grade, according to body height, most of the students are $160-180 \mathrm{~cm}$ tall and we can say that, according to their age, this is a normal height, but they are still growing.

During measuring 13 students from the regional school "Ss Cyril and Methodius" in thevillage Podlog we could see that according to their height they are in the same rank as the previous respondents, so we can conclude that there is no difference in the height of studentsof the same age.

During weight measurement, the students from the ninth grade from the two schools "Ss Cyril and Methodius" in Kocani and the regional school "Ss Cyril and Methodius" in the village of Podlog were also measured.

The total number of students who were measured from the primary school "Ss Cyril and Methodius" in Kocani is 44. Based on this, we can see that the prevailing students are those that weigh $40-60 \mathrm{~kg}$, so we can conclude that this is a normal weight, and we should strive through advice and guidelines to show students how they can maintain their weight in their future period of adolescence and growth. From the measurement conducted on the students from the primary school "Ss Cyril and Methodius" in the village of Podlog, 13 students' weight is in the range of 40-60 kg. In general, there is no big difference between the ninth- grade students in terms of height and weight; they are within the normal range, but this is stilla category of respondents who are still in the phase of growth and development and who constantly add and subtract certain habits in their normal life. Thus, we think that guidelines and practical lectures on healthy eating and maintaining a normal BMI would be of particular importance so that in future they can develop properly.

The table 9 below shows the results obtained from the measurements of body height and weight of the respondents from the first grade of the primary school "Ss Cyril and Methodius" in Kocani, as well as their gender, whether they do sports or not etc., so, based on these indicators, BMI and BMI percentiles are determined for each respondent individually.

It is evident from the table that girls who engage in sports have a malnourished BMI and normal to increased BMI percentiles, unlike girls who do not engage in sports and have an increased BMI and also have more than the allowed limit for BMI percentiles, which indicates obesity. Boys who do not play sports also have a malnutrition BMI and the risk of obesity expressed in BMI percentiles; in contrast to this indicator, among boys who engage insports an indicator of malnutrition appears as BMI, and normal body weight that is at risk of passing in overweight as BMI percentiles. 
Maintaining normal body weight and BMI percentiles is important for the developmentand health of children as well as adults. In the way we individually create our life in modern living conditions, we often forget the basic rules that we must adhere to in order to maintain the level of optimal body weight. Healthy eating and sports activities are some of the importantconditions that contribute to normal body weight.

In support of this research, the graphical presentation and the scale for interpretation of BMI and BMI percentile are given, according to which the above findings are explained forthe students from the first grade.

Table 10. BMI and BMI Percentile - Kocani first grade

\begin{tabular}{|c|c|c|c|c|c|c|}
\hline $\begin{array}{c}\text { First } \\
\text { grade }\end{array}$ & height & weight & sex & sport & BMI & BMI percentile \\
\hline 1 & 123 & 25,5 & M & no & $\mathbf{1 6 , 9}$ & 82,9 \\
\hline 2 & 119 & 19,0 & F & yes & $\mathbf{1 3 , 4}$ & 4,8 \\
\hline 3 & 118 & 19,5 & F & no & $\mathbf{1 4 , 0}$ & 15,6 \\
\hline 4 & 119 & 21,0 & M & no & $\mathbf{1 4 , 8}$ & 31,9 \\
\hline 5 & 123 & 28,0 & F & yes & $\mathbf{1 8 , 5}$ & 93,9 \\
\hline 6 & 122 & 24,0 & F & no & $\mathbf{1 6 , 1}$ & 71,2 \\
\hline 7 & 120 & 32,0 & F & no & $\mathbf{2 2 , 2}$ & 99,0 \\
\hline 8 & 120 & 25,0 & M & no & $\mathbf{1 7 , 4}$ & 88,7 \\
\hline 9 & 80 & 21,0 & F & yes & $\mathbf{3 2 , 8}$ & 99,9 \\
\hline 10 & 110 & 36,0 & M & no & $\mathbf{2 9 , 8}$ & 99,9 \\
\hline 11 & 129 & 28,0 & F & no & $\mathbf{1 6 , 8}$ & 82,1 \\
\hline 12 & 128 & 28,0 & M & yes & $\mathbf{1 7 , 1}$ & 85,8 \\
\hline 13 & 114 & 21,0 & M & no & $\mathbf{1 6 , 2}$ & 70,9 \\
\hline 14 & 126 & 25,0 & F & no & $\mathbf{1 5 , 7}$ & 63,7 \\
\hline 15 & 125 & 25,0 & M & yes & $\mathbf{1 6 , 0}$ & 67,0 \\
\hline 16 & 82 & 26,0 & M & no & $\mathbf{3 8 , 7}$ & 99,9 \\
\hline 17 & 127 & 36,0 & F & no & $\mathbf{2 2 , 3}$ & 99,0 \\
\hline 18 & 160 & 52,0 & F & no & $\mathbf{2 0 , 3}$ & 97,7 \\
\hline 19 & 120 & 25,0 & F & no & $\mathbf{1 7 , 4}$ & 87,3 \\
\hline 20 & 121 & 24,0 & M & no & $\mathbf{1 6 , 4}$ & 75,5 \\
\hline 21 & 111 & 21,0 & F & yes & $\mathbf{1 7 , 0}$ & 84,4 \\
\hline 22 & 123 & 20,0 & F & yes & $\mathbf{1 3 , 2}$ & 2,9 \\
\hline 23 & 130 & 25,0 & F & yes & $\mathbf{1 4 , 8}$ & 37,4 \\
\hline & & & & & & \\
\hline
\end{tabular}

Out of 23 respondents - students from the first grade, obesity was found in 6, which is approximately $30 \%$ of the total number.

The calculated mean value of the students' body height is $120 \mathrm{~cm}$, the standard deviation is 15 .

$$
\sigma=\sqrt{ }^{1} \sum^{n}(x-x)^{2}
$$

$\mathrm{n}$ - number of elements in the sample

$x$ - arithmetic mean of the sample

$x_{i i}$ - member of the sample 


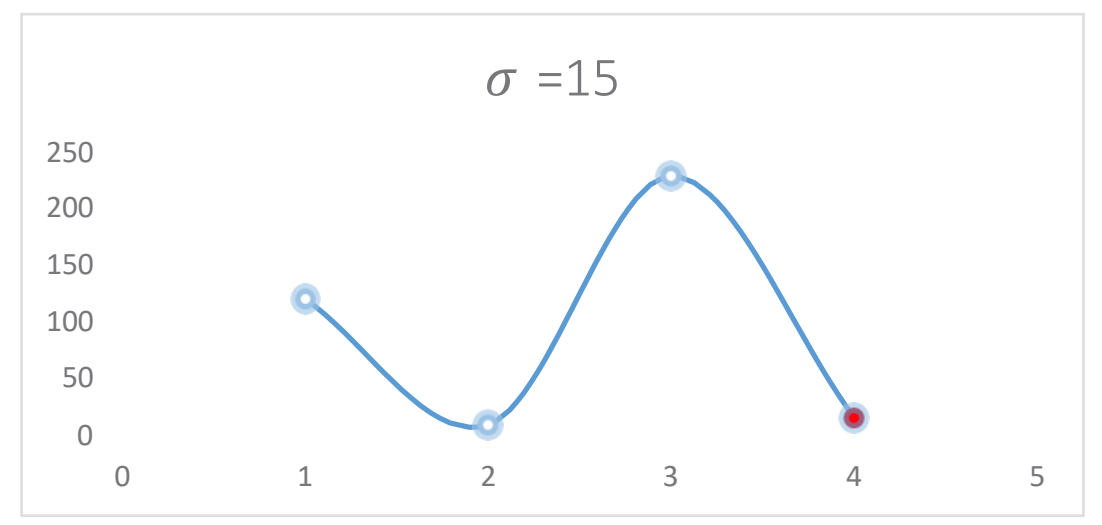

Table 11. Scale for the interpretation of BMI and BMI percentile

\begin{tabular}{|c|c|c|}
\hline BMI index & BMI percentile & Interpretation \\
\hline Less than 18,5 & $<5$ & Malnutrition \\
\hline $18,5-24,9$ & $5-85$ & Normal \\
\hline $25-29,9$ & $85-95$ & Increased weight \\
\hline 30 or more & $>95$ & Obesity \\
\hline
\end{tabular}

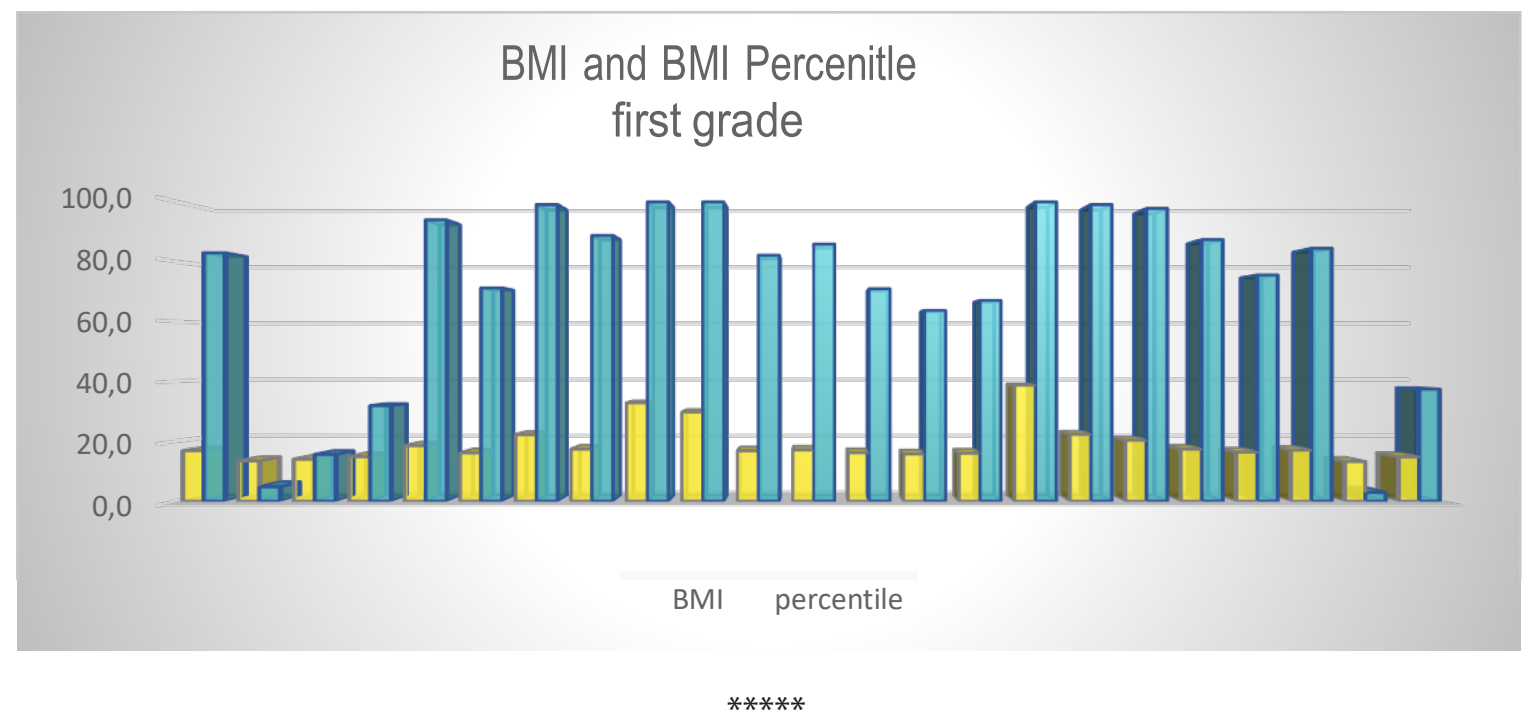

Chart 2. BMI end BMI Percentile - Kocani first grade

According to the research conducted in the fourth grade, it can be noticed that the girlswho engage in sports have an undernourished BMI index and normal BMI percentiles, whereas this is not the case with the female respondents who answered that they do not engage in sports. Here BMI rises from normal to increased body weight. In the malerespondents who answered that they were engaged in sports and sports activities, BMI ranges from undernourished to normal, while those who answered that they did not engage in sportsand sports activities belong to the group of increased BMI and in the group of obesity expressed in BMI percentiles. 


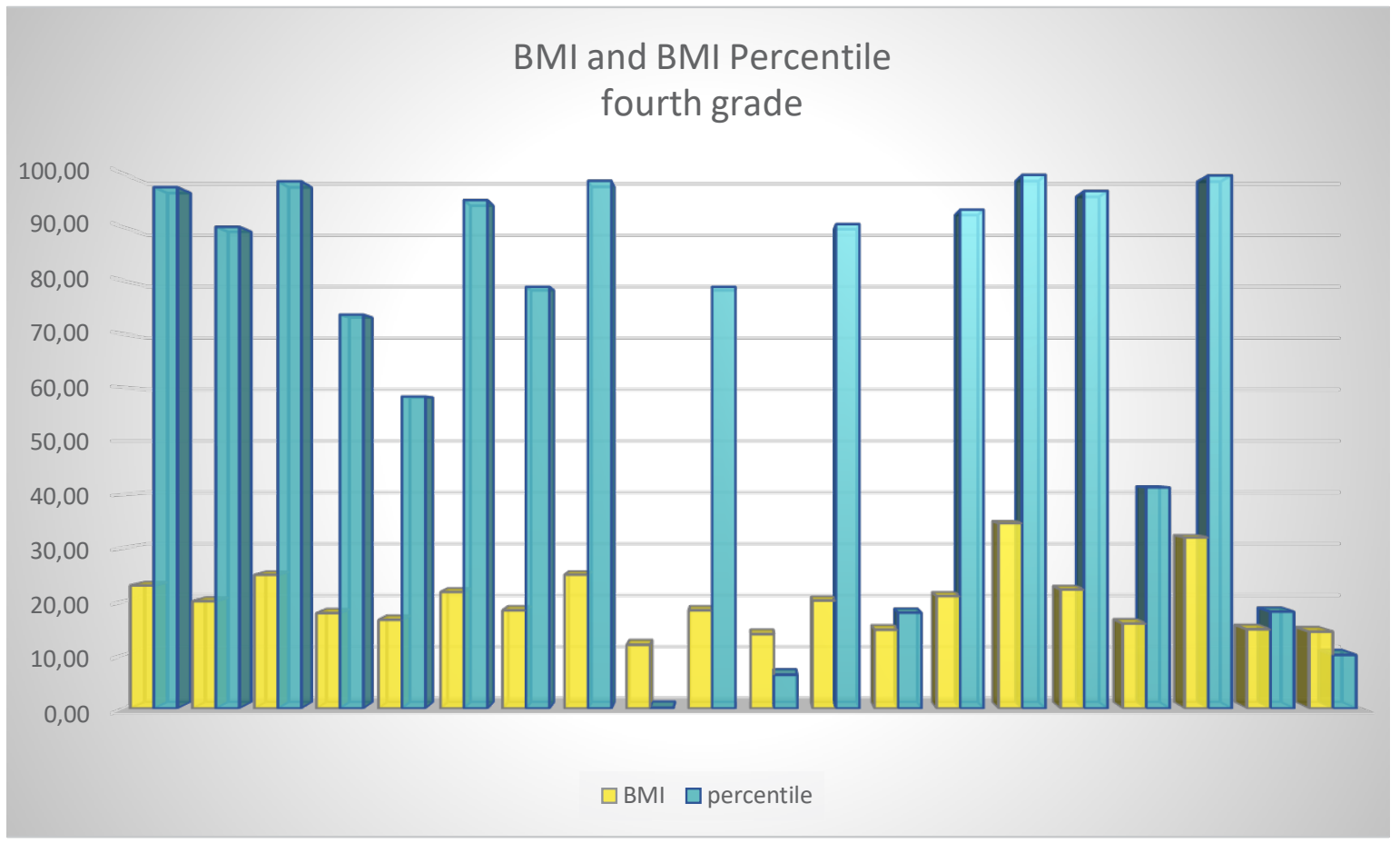

Chart 3. BMI and BMI Percentile - Kocani fourth grade

From the survey conducted in the ninth grade, the female respondents whoanswered that they engaged in sports and sports activities had a normal BMI index and normalBMI percentiles, while in the respondents who did not engage in sports and sports activities the BMI index was normal, but BMI percentiles ranged from normal to increased body weight.In the respondents from the ninth grade, in the boys who engaged in sports and sports activities, the BMI index was normal, while the BMI percentiles in a certain group were normaland moved towards increased weight, while in male respondents who did not engage in sportsand sports activities the BMI was normal towards obesity and the BMI percentiles gave the same result.

\section{Occurrence, frequency and treatment of some of the most common diseases and deformities in school children compared inurban and rural environment}

The modern way of life that is possible due to advanced technology has imposed a significant reduction in physical activity among the entire population, and especially among school-age children, which is characterized by a long stay in school, sitting and working on school desks and computers, as well as the more frequent use of various motor vehicles whenperforming numerous daily activities. All this contributes to physical passivity in children, which directly affects the weakening of their musculoskeletal system, as well as the occurrence of obesity, which is a sure prerequisite for the occurrence of various deformities of the spine, feetand other parts of the body.

School age is a time of constant growth and development. Physical activity during thedevelopment phase strengthens the fundamental skills needed to lead a healthy and active life as an adult. These skills include, but are not limited to, agility, balance, coordination, and endurance. Learning and developing these abilities also has an extraordinary effect on children's self-confidence, which also enables a constant sense of success and independence. At this age it is recommended that children perform physical activity in as many ways as possible: active play, organized and unorganized sports activities, games, physical education and other activities, at home and at school.

\section{Reasons affecting the occurrence of incorrect body posture anddeformities in children}

Poor posture habits, hereditary factors, insufficient physical activity, heavy school backpacks, and inadequate school desks lead to impaired statics of the spine and other partsof the locomotor system. 
As a result, the most common spinal deformities such as kyphosis, lordosis, scoliosis, and flat feet occur. The sudden growth of the bones of the child at pubertyalso has a negative impact on the already present deformities.

Improper posture can be influenced by factors of various nature: developmental abnormalities, decrease in muscle power, poor diet, obesity, psychological conditions, pathological conditions etc. In such situations, bad posture habits appear, and to improve thiscondition a longer period is needed. Daly exercise is necessary for longer periods by applyingadequate physical exercises that will affect the nervous-muscular system by changing the habits of posture and movement.

As improper posture is often the result of muscle weakness in the lumbar spine, poor circulation, etc., it can be corrected through muscle strength exercises that will strengthen thepostural muscles.

The occurrence of improper posture and deformities are also influenced by certain pathological conditions, which lead to functional and structural abnormalities of the locomotorsystem, such as: physical defects that affect the weakening of bone and muscle structure, hearing and vision problems, as well as cardiovascular disorders, neuromuscular problems, and arthritis that are more common in the elderly. In children, improper posture often occurs as a result of bad habits that children easily adopt. Furthermore, sitting for many hours in school desks, inappropriate school supplies, and writing homework at home, additionally tire the muscles of the body, so it is easy to take incorrect postures that momentarily have a relaxing effect.

The analysis of the occurrence, frequency and treatment of some of the most commondiseases and deformities in school children compared in urban and rural areas was performedbased on the results of systematic health checks carried out in schools to get an idea of the health status of the young population.

Table 12 shows the results of the students' systematic health checks in the primary school "Ss Cyril and Methodius" in Kocani.

Table 12. Results from the students' systematic health checks in the primary school "Ss Cyril and Methodius" in Kocani

\begin{tabular}{|l|c|c|c|c|c|c|c|c|}
\hline & \multicolumn{6}{|c|}{ Primary school "Ss Cyril and Methodius" in Kocani } \\
\hline Class & \multicolumn{2}{|c|}{} & \multicolumn{2}{|c|}{ IV } & \multicolumn{3}{|c|}{ IX } & \multicolumn{3}{c|}{ Total } \\
\hline Students (male-female) & $\mathrm{m}$ & $\mathrm{f}$ & $\mathrm{m}$ & $\mathrm{f}$ & $\mathrm{m}$ & $\mathrm{f}$ & $\mathrm{m}$ & $\mathrm{f}$ \\
\hline Lice & $/$ & $/$ & $/$ & $/$ & $/$ & $/$ & $/$ & $/$ \\
\hline Poor posture & 3 & 11 & 9 & 11 & 18 & 21 & 30 & 43 \\
\hline Poor nutrition & $/$ & 2 & 3 & 1 & 7 & 5 & 10 & 8 \\
\hline Spinal deformities & $/$ & $/$ & 4 & 5 & 14 & 17 & 18 & 22 \\
\hline Deformities of the chest & $/$ & $/$ & 1 & 2 & 5 & 4 & 6 & 6 \\
\hline Deformities of the feet & 9 & 7 & 11 & 10 & 15 & 19 & 35 & 36 \\
\hline Deformities of the foreheat & 1 & 3 & 4 & 4 & 12 & 14 & 17 & 21 \\
\hline Visual abnormalities & 1 & 4 & 4 & 2 & 7 & 12 & 12 & 18 \\
\hline Hearing impairment & 1 & $/$ & $/$ & $/$ & $/$ & $/$ & 1 & 0 \\
\hline Heart defects & 1 & 8 & 6 & 6 & 3 & 5 & 10 & 19 \\
\hline Speech defects & 1 & 2 & 7 & 3 & 2 & 4 & 10 & 9 \\
\hline Insufficient mental health & $/$ & $/$ & $/$ & $/$ & $/$ & $/$ & 0 & 0 \\
\hline Anemia & 3 & 7 & 3 & 1 & 2 & 3 & 8 & 11 \\
\hline
\end{tabular}

During the systematic health checks of the students from the primary schools in $2018 / 2019$, the following pathological conditions were determined: deformities of the foot were registered in 77 students, or in $87 \%$ of the examined students. The deformities of the spine follow; however, in none of the students of the first grade the occurrence of this type of deformity has been registered, while 
in the students of the fourth grade it has been registered in 9 students, and in the ninth grade in 31 students. Regarding the deformities of the chest, inthe first grade there is no such occurrence, in the fourth it occurs in three students, and in theninth grade in 9 students. In percentage terms, chest deformities occur in $13 \%$ of students, which is three times less $(0.45 \%)$ than deformities of the spine. This phenomenon is influenced by several endogenous and exogenous factors, which could be the subject of further researchfor a more detailed analysis.

From the results it is clear that the most common deformities are the deformities of thefeet and the spine. The first grade is the period when children start school and in that period no spinal deformities are registered in any child of both sexes, while in the fourth and ninth grade the number significantly increases. This occurrence is due to the fact that, when children start school, it is the beginning of a new load on the movement apparatus. Staying in school restricts movement which is a prerequisite for improper growth and development. Long-term static load that results in a decrease in motor activities and higher intellectual demands of school negatively affect both functional and morphological changes, as well as the mental state of the child.

The analysis of the results shows an increase of a 3-4 times higher number of students with clearly expressed deformities in the ninth grade compared to the results obtained in the respondents in the fourth grade ( 14 students in the ninth versus 4 students in the fourth grade). The period of puberty is one of the most sensitive stages in the development of a child's organism. There is a characteristic sudden elongation of the bones that the muscles cannot follow. In addition, there is increased hormonal activity and neuromotor sensitivity. Due to these reasons, the movement apparatus becomes overloaded, resulting in improper posture. The results from the systematic health checks of students in the primary school "Ss

Cyril and Methodius" in Kocani indicate that the deformities of the spine are increasing year

by year. The fragile musculoskeletal system in developing children is influenced by internal and external factors that lead to impaired spinal statics and the occurrence of scoliosis, kyphosis and lordosis, as well as deformities of the feet.

During the systematic health checks of students from primary schools in the 2018/2019school year, the following pathological conditions were determined: foot deformities were registered in 71 students out of the 88 students examined. The feet are the basis for the rest of the body and any deformity caused of exogenous or endogenous nature makes a change in terms of statics and body dynamics. Deformed feet also cause mechanical changes, excessive load on the front of the foot that causes new difficulties on the higher parts of the body.

This is followed by deformities of the spine and chest, which are present in 40 studentsout of the total number examined (88). Then follows poor posture in 52 students (out of 88 ) or $59 \%$ of the total examined students. Any deviation from the normal physiological curvature ofthe spine usually leads to kyphosis, scoliosis, and lordosis. Spinal deformities, in addition to leading to aesthetic changes in the body, also cause serious disorders of physical and mentalhealth. The challenges of modern civilization require a complete adaptation of anthropometric,motor, and functional development. Deformities are most often acquired during the developmental period and that is why their early detection is the key to successful correction. 
Table 13. Results from the systematic health checks of the students from the primary school "SsCyril and Methodius" in Podlog

\begin{tabular}{|l|c|c|c|c|c|c|c|c|}
\hline & \multicolumn{6}{|c|}{ "SSCyril and Methodius" village of Podlog } \\
\hline Class & \multicolumn{2}{|c|}{} & \multicolumn{2}{|c|}{ IV } & \multicolumn{3}{|c|}{ IX } & \multicolumn{2}{c|}{ Total } \\
\hline Students (male-female) & $\mathrm{m}$ & $\mathrm{f}$ & $\mathrm{m}$ & $\mathrm{f}$ & $\mathrm{m}$ & $\mathrm{f}$ & $\mathrm{m}$ & $\mathrm{f}$ \\
\hline Lice & $/$ & $/$ & $/$ & $/$ & $/$ & $/$ & $/$ & $/$ \\
\hline Poor posture & 1 & 3 & 3 & 1 & 1 & 6 & 5 & 10 \\
\hline Poor nutrition & 1 & $/$ & 3 & 1 & 3 & 2 & 7 & 3 \\
\hline Spinal deformities & $/$ & $/$ & $/$ & $/$ & $/$ & 4 & $/$ & 4 \\
\hline Deformities of the chest & $/$ & $/$ & $/$ & $/$ & $/$ & 1 & $/$ & 1 \\
\hline Deformities of the feet & $/$ & 1 & 1 & 2 & $/$ & 1 & 1 & 4 \\
\hline Deformities of the foreheat & 1 & 3 & 1 & $/$ & 1 & 1 & 3 & 4 \\
\hline Visual abnormalities & 3 & $/$ & $/$ & $/$ & $/$ & 3 & 3 & 3 \\
\hline Hearing impairment & $/$ & $/$ & $/$ & $/$ & $/$ & $/$ & $/$ & $/$ \\
\hline Heart defects & 1 & $/$ & 1 & 2 & $/$ & 1 & 2 & 3 \\
\hline Speech defects & 2 & 1 & 1 & $/$ & $/$ & 1 & 3 & 2 \\
\hline Insufficient mental health & $/$ & $/$ & $/$ & $/$ & $/$ & $/$ & $/$ & $/$ \\
\hline Anemia & 1 & $/$ & $/$ & 2 & $/$ & $/$ & 1 & 2 \\
\hline
\end{tabular}

From the analysis of the results given in the table, obtained from the systematic healthchecks of the students in the village of Podlog, it can be seen that the most numerous deformity is poor body posture. Out of 37 students, in 15 students this phenomenon was noticed, or this phenomenon was registered in $40 \%$ of the respondents. This is followed by the deformities of the spine (in 7 students). Poor body nutrition is evident, which is registeredin 10 out of 37 students.

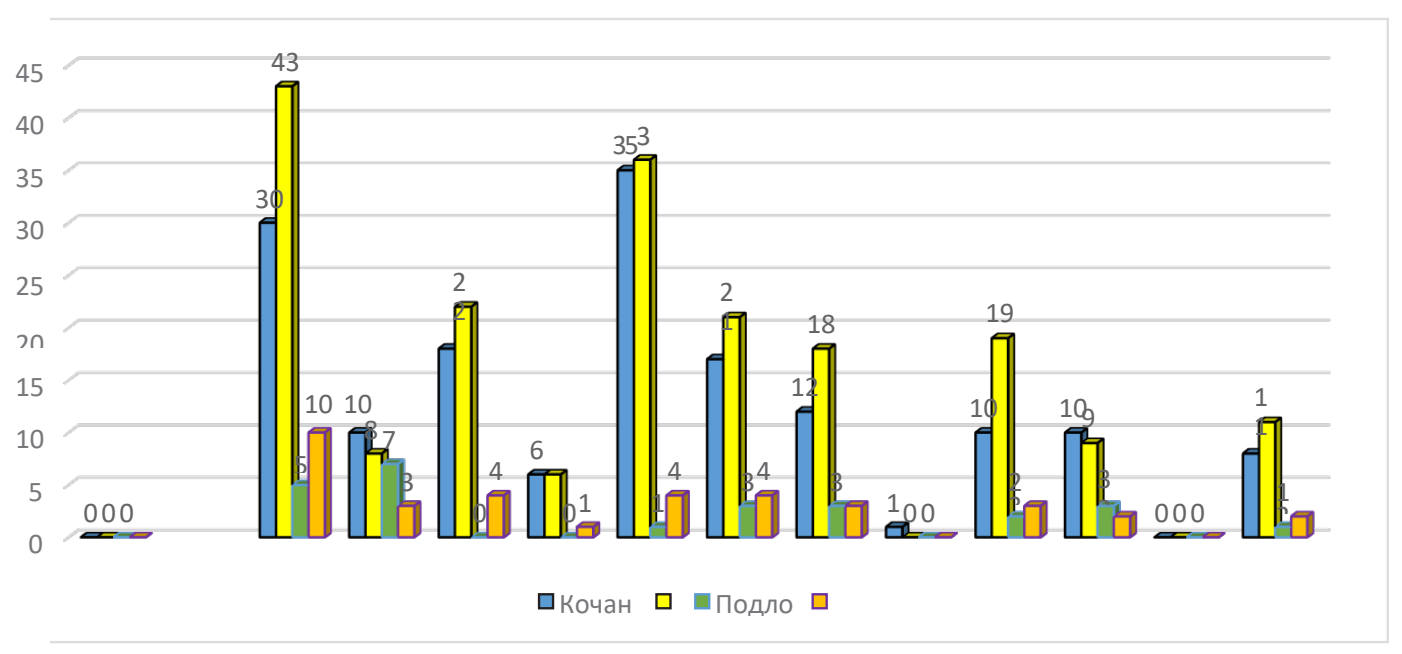

Chart 4. Comparison between results of systematics reviews OU "Cyril and Metodius"Kocani and OU "Cyril and Metodius"Podlog 


\section{Conclusion}

From the research we can conclude that the sociometric status of students has an exceptional impact (directly and indirectly) on the social, emotional, cognitive aspects of the person, as well as on the educational success / failure in children and young people.

We can point out the following main sub-points of the conclusion of our research:

- The most important thing is to maintain a healthy body weight and to prevent it from gaining instead of allowing weight gain, and later losing weight because thisrequires extreme effort and a longer period of time.

- Practicing sport and engaging in sports activities contributes to a sustainable BMland has an impact on the health of both children and adults.

- Raising awareness in children and parents to ensure a healthy life through a healthy diet, and thus a normal BMI.

- The most common form of family that prevails today is composed of a mother, afather and children.

- The quality of family relationships is an important factor of proper growth and development.

- Parents, i.e. family, are a major factor in formulating attitudes in children.

The key elements of the socioeconomic status are:

- material status,

- education,

- work status.

We can emphasize that the difference between the urban and rural environment is obvious, that due to certain advantages that the urban environment brings, children have greater opportunities for socialization. However, modern trends impose a dynamic life style where more and more parents of children from rural areas with a higher social status try to provide them with approximately same opportunities for leisure activities and thus take them to urban areas for various additional classes and activities.

\section{References}

Adachi-Mejia AM, Longacre MR, Gibson JJ, Beach ML, Titus-Ernstoff LT, Dalton MA. Children with a TV in their bedroom at higher risk for being overweight. Int J Obes (Lond) 2007;31(4):644-651

https://doi.org/10.1038/sj.ijo.0803455

Colhoun, H., Hemingway, H. and Poulter, N.R. (1998) Socioeconomic status and blood pressure: an overview analysis. Journal of Human Hypertension 12, pp.91-110.

https://doi.org/10.1038/sj.jhh.1000558

Flegal., K.M., Carroll, M.D., Ogden, C.L., and Johnson C.L. (2002) Prevalence and trends in obesity among US adults 1999-2000. Journal of American Medical Association 288(14), pp.1723-7

https://doi.org/10.1001/jama.288.14.1723

Gail, D.H., Gloria. A.A. and Bern'Nadette, K. (2005) Obesity and theAfrican-American adolescent in Mississippi:anoverview. Southern Medical Journal 98(1), pp.72-78.

Hardy, R., Wadsowrth, M., Kuh, D. (2000) The influence of childhood weight and socioeconomic status change in adult body mass index in a British national birth cohort.

International Journal of Obesity and Related Metabolic Disorders 24(6), pp.725-34, https://doi. org/10.1038/sj.ijo.0801238

Harrison K, Marske AL. Nutritional content of foods advertised during the television programs children watch most. Am J Public Health. 2005;95(9):1568-1574. https://doi.org/10.2105/ ajph.2004.048058

Hedley AA, Ogden CL, Johnson CL, Carroll MD, Curtin LR, Flegal KM. Prevalence of overweight and obesity among US children, adolescents, and adults, 1999- 2002. JAMA. 2004;291(23):28472850, https://doi.org/10.1001/jama.291.23.2847

Hill, J.O., Wyatt, H.R., Melanson, E.L. (2000) Genetic and environmental contributions to obesity. Medical Clinic of North America 84(2) 333-46 https://doi.org/10.1016/s0025-7125(05)70224-8 
Himes, J.H. (1999) Agreement among anthropometric indicators identifying the fattest adolescents. International Journal of Obesity 23(2), pp.18-21. https://doi.org/10.1038/sj.ijo.0800854

Jackson C, Brown JD, L'Engle KL. R-rated movies, bedroom televisions, and initiation of smoking by white and black adolescents. Arch Pediatr Adolesc Med. 2007;161(3):260- 268, https://doi. org/10.1001/archpedi.161.3.260

Kuczmarski, R.J., Flegal., K.M. (2000) Criteria for definition of overweight in transition: background and recommendations for the United States. American Journal of Clinical Nutrition 72, pp.1074-81. https://doi.org/10.1093/ajcn/72.5.1074

Luo J, Hu FB. Time trends of obesity in pre-school children in China from 1989 to 1997. Int J Obes Relat Metab Disord. 2002;26(4):553-558. https://doi.org/10.1038/sj.ijo.0801944

Lyratzopoulos, G., McElduff, P., Heller, R.F., Hanily, M. and Lewis, P.S. (2005) Mid-term body mass index increase among obese and non-obese individuals in middle-life and deprivation status. BMC Public Health 5, pp.32. https://doi.org/10.1186/1471-2458-5-32

Maes, H.H.M., Neale, M.C. and Eaves, L.J. (1997) Genetic and environmental factors in relative body weight and human adiposity. Behavior Genetics 27, pp.325-351

McGee, R.; Brock, K. (2001) From poverty assessment to policy change: processes, actors and data. Brighton: Institute of Development Studies.

Sarlio-Lähteenkorva S, Lissau I, Lahelma E. The social patterning of relative body

weight and obesity in Denmark and Finland. Eur J Public Health. 2006;16(1):36-40.

Siedel, J.C. (1997) Time trend in obesity: an epidemiological perspective. Horm Metab Res 29, pp.155158.

Sobal, J. and Stunkard, A.J. (1989) Socioeconomic status and obesity: a review of the literature. Personality and Social Psychology Bulletin 105, pp.260-75. https://doi.org/10.1037/0033-2909.105.2.260

Sorenson, T.I.A. (2000) The changing lifestyle in the world; body weight and what else.

Diabetic Care 23(2), pp.1-4

Padez C, Fernandes T, Mourão I, Moreira P, Rosado V. Prevalence of overweight and obesity in 7-9year-old Portuguese children: trends in body mass index from 1970- 2002. Am J Hum Biol. 2004;16(6):670-678. https://doi.org/10.1002/ajhb.20080

Popkin, B.M. (1994) The nutrition transition in low income countries: an emerging crisis.

Nutr Rev 52, pp.285-298

Uwaifo, G. and Arioglu, E. (2006). Retrieved from: www.emedicine.com/med/topic1653.htm.

World Health Organization (2000) Defining the problem of overweight and obesity. In: World Health Organization. Obesity: preventing and managing the global epidemic: report of a WHO Consultation. Geneva. pp.241-3. https://doi.org/10.1017/s0021932003245508

(WHO Technical Report Series, 894). World Health Organization (WHO) (1998) Obesity: preventing and managing the global epidemic. Report of a WHO Consultation. Presented at the World Health Organization, June 3-5, 1997; Geneva, Switzerland. Publication WHO/NUT/NCD/98. 1:1998 https://doi.org/10.1017/s0021932003245508

Zimmermann MB, Gübeli C, Püntener C, Molinari L. Overweight and obesity in 6-12-year-old children in Switzerland. Swiss Med Wkly. 2004;134(35-36):523-528. 